\title{
Thrombotic Thrombocytopenic Purpura Refractory to Plasmapheresis Treated Successfully with Vincristine: A Case Report
}

\author{
Walid H. Elrewihby ${ }^{\star}$, Salwa Zaghloul, Nivin Saber, Emad Eldin Hasan and Adel Elattar
}

Department of Nephrology, Damanhour Medical National Institute, Damanhour, Egypt

*Corresponding author: Elrewihby WH, Department of Nephrology, Damanhour Medical National Institute, Damanhour, Egypt, Tel: +201222819225; E-mail: whemida@yahoo.com

Received date: March 27, 2017; Accepted date: April 18, 2017; Publication date: April 22, 2017

Copyright: ( $) 2017$ Elrewihby HW, et al. This is an open-access article distributed under the terms of the Creative Commons Attribution License, which permits unrestricted use, distribution, and reproduction in any medium, provided the original author and source are credited.

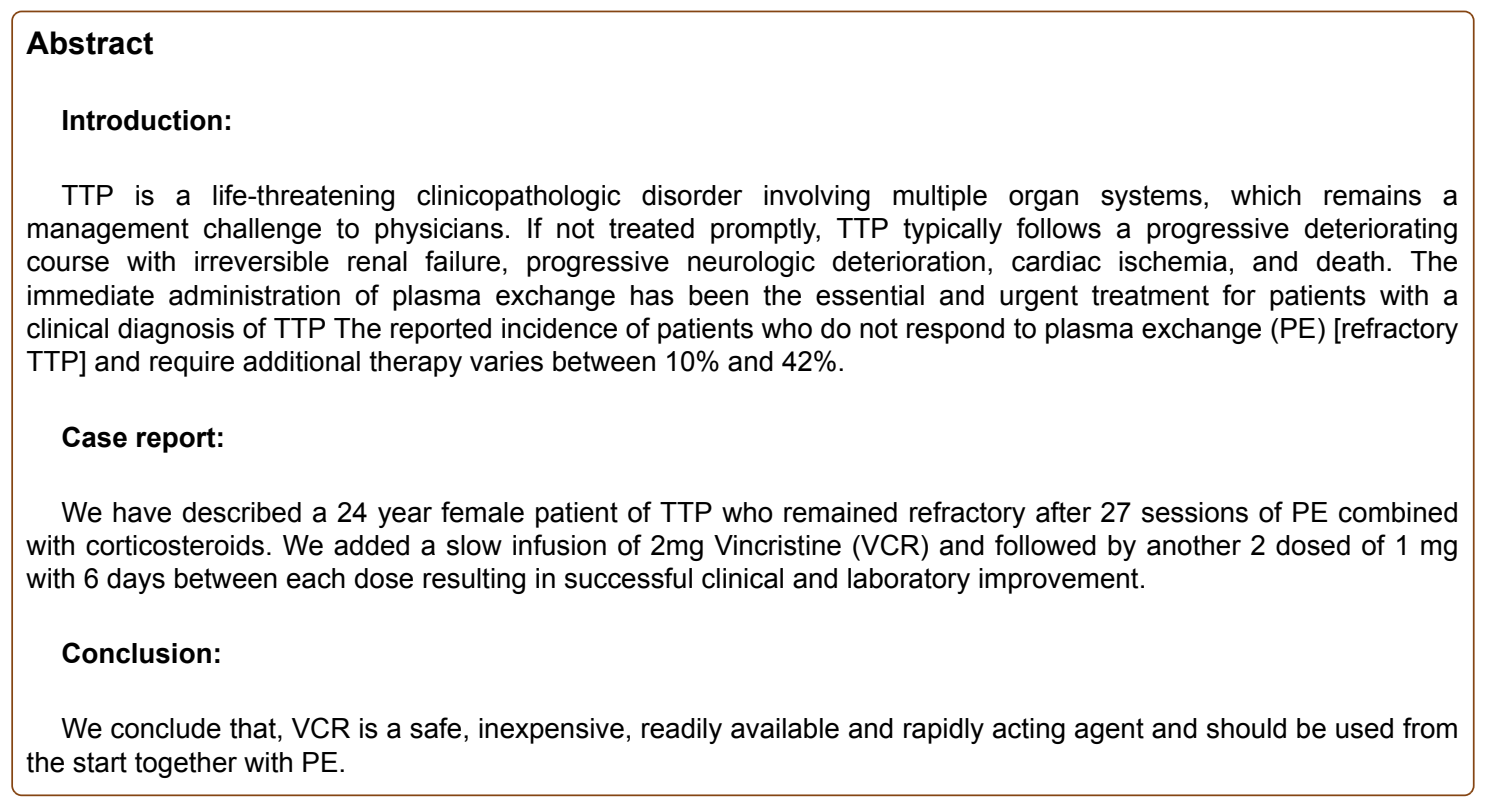

\section{Keywords:}

Thrombotic thrombocytopenic purpura, Plasmapheresis, Vincristine, Refractory TTP

\section{Introduction}

Thrombotic Thrombocytopenic Purpura (TTP) has a specific pathogenetic defect characterized by the inability to cleave ultralarge vWF (ULvWF) [1]. They are normally cleaved by a metalloprotease, ADAMTS13 (a disintegrin and metalloprotease with thrombospondin type 1 domain 13) [2]. Low ADAMTS13 activity can result from a constitutive deficiency or circulating acquired IgG autoantibodies to different antigenic regions of the ADAMTS13 molecule in patients with acute TTP. The pathogenetic role of this autoantibody is supported by its disappearance from the circulation when remission is achieved by effective treatment [3]. The classic clinical pentad: fever, thrombocytopenia, hemolytic anemia, neurologic symptoms, and renal failure were described in a review of 271 published cases in 1964 . Mortality is $~ 90 \%$ in untreated cases [4]. After the introduction of plasma exchange (PE) in the 1980s, TTP patient survival rates increased to $70-90 \%$ [5]. About $20 \%$ of TTP are resistant to plasma exchange[6-9].
We describe a patient presenting with a first episode of acute refractory TTP in whom remission was not achieved by PE \& steroids who was successfully treated with vincristine (VCR).

\section{Case Report}

A 24-year old female, presented to our department with pallor, fatigue, and headache. She had no past medical history, except she was on diet regimen to decrease her weight one year ago and stopped after 2 months only ( her weight on presentation was $110 \mathrm{~kg}$, BMI: $38.2 \mathrm{~kg} /$ $\mathrm{m}^{2}$ ). No any abnormality observed by examination, except pallor and ecchymotic rash on her lower limbs. Laboratory investigations revealed severe anemia $\mathrm{Hb}$ : $7.5 \mathrm{gm} / \mathrm{dl}$, thrombocytopenia PLT: 9,000 $/ \mathrm{mm}^{3}$ and WBC: $11,800 / \mathrm{mm}^{3}$. A peripheral blood smear was showing schistocytes, fragmented red blood cells and anisopoikilocytosis. Reticulocytes were $21 \%$, ESR was 24/62, LDH: $3000 \mathrm{U} / \mathrm{L}$, total bilirubin: $2.5 \mathrm{mg} / \mathrm{dl}$ and the indirect: $1.5 \mathrm{mg} / \mathrm{dl}$. Direct Coomb's test was negative, and coagulation profile was normal. Urine analysis revealed microscopic hematuria but no proteinuria. Serum creatinine and liver function tests were within normal limits and HIV, HbsAg, $\mathrm{HCV}$ were negative. Lupus anticoagulant, ANA and anti-dsDNA antibodies and were negative.

A diagnosis of TTP was established and we started Therapeutic Plasma Exchange of one plasma volume with fresh frozen plasma daily for 7 days together with oral administration of prednisolone $(60 \mathrm{mg} /$ 
day), until the platelets count reached $>150,000$. The plasma exchange regimen changed to one plasma volume every other day instead of daily with daily $\mathrm{CBC}$ follow up. We found that the platelets count started to decrease again reaching $47,000 / \mathrm{mm}^{3}$ then $9,000 / \mathrm{mm}^{3}$. So we restarted PE again daily and pulse steroids were given (methylprednisolone $500 \mathrm{mg} /$ day for 3 days) followed by oral prednisolone $80 \mathrm{mg} /$ day. But, unfortunately after another sixteen $\mathrm{PE}$ sessions the platelets count didn't exceed $30,000 / \mathrm{mm}^{3}, \mathrm{Hb}: 8.7 \mathrm{gm} / \mathrm{dl}$ and $\mathrm{LDH}$ rose to reach $5000 \mathrm{u} / \mathrm{l}$.

After exclusion of other causes associated with poor response to PE like infection and after a total 27 sessions of PE, the patient's hemolysis and thrombocytopenia did not resolve, we have considered it as Thrombotic Thrombocytopenic Purpura refractory to steroids \& plasmapheresis.

So, vincristine (VCR) treatment was started in addition to PE. The VCR was given as follows: a slow infusion over $6 \mathrm{~h}$ of $2 \mathrm{mg}$ on day 1 followed by $1 \mathrm{mg}$ on days 7 and 13. After three doses of VCR with continuation of the PE therapy, the hemolysis and thrombocytopenia resolved. The platelets count reached $175,000 / \mathrm{mm}^{3}$ after the second dose of VCR and clinically the patient improved with tapering of PE twice /week. After the third dose of VCR the platelets count increased to $233,000 / \mathrm{mm}^{3}$. We have discharged patient and on follow up after one month, platelet counts were $251,000 / \mathrm{mm}^{3}$.

\section{Discussion}

TTP is a life-threatening clinicopathologic disorder involving multiple organ systems, which remains a management challenge to physicians. If not treated promptly, TTP typically follows a progressive deteriorating course with irreversible renal failure, progressive neurologic deterioration, cardiac ischemia, and death $[10,11]$. The immediate administration of plasma exchange has been the essential and urgent treatment for patients with a clinical diagnosis of TTP since the publication of the randomized clinical trial by the Canadian Apheresis Group in 1991[12]. The reported incidence of patients who do not respond to PE (refractory TTP) and require additional therapy varies between $10 \%$ and $42 \%$ [13-16]. In much of that literature, refractory TTP is defined as a failure of platelet response after 4 to 7 days of $\mathrm{PE}$, or a clinical deterioration in a patient receiving standard therapy [17]. Treatment of these refractory TTP patients poses therapeutic dilemma as most evidence in this setting is limited to case reports and case series. Salvage options include high-dose immunoglobulin [18], rituximab [19], immunosuppressive agents [e.g. cyclophosphamide [20], cyclosporine [21], autologous stem cell transplantation [22] and splenectomy [23].

Successful vincristine use has been described in various small studies and case reports, usually as a rescue therapy in refractory TTP [17, 24-33].

Vincristine, a vinca alkaloid generally used as chemotherapy. Evidence of the efficacy of VCR in treating TTP first became available in the late 1970s [35]. VCR prevents the interaction between damaging immunoglobulin $G$ antibodies and endothelial cells. Furthermore, VCR is known to alter PLT membrane glycoprotein receptors preventing their up regulation and binding of von Willebrand factor (VWF) multimers, thereby reducing PLT aggregation [36].

Our patient received VCR after 27 sessions of PE. The platelet count began to increase reaching $65,000 / \mathrm{mm}^{3}$ after 3 days of starting VCR and $175,000 / \mathrm{mm}^{3}$ after 8 days. The total dose of VCR given to the patient was $4 \mathrm{mg}$ without apparent side effects and this agrees with some studies using doses ranging from $2 \mathrm{mg}$ up to $14 \mathrm{mg}$ (24-34). Ziman et al, reported 100 percent survival in their retrospective data of 12 TTP patients (PLT counts ranging $4,000 / \mathrm{mm}^{3}$ to $36,000 / \mathrm{mm}^{3}$ ) treated with standardized protocol of PE and VCR without side effects. This report is also parallel with their valuable review of literature that demonstrated a significant advantage in durable remission rates in patients treated with combination TPE and VCR as initial therapy compared to patients treated with TPE without VCR. In a literature review that involved 56 studies and 105 patients, stable remission was obtained in $73 \%$ of patients receiving vincristine as secondary or salvage therapy (ie, $>3$ days following diagnosis), with adverse events in only $5.7 \%$ of patients(36). These studies were retrospective and uncontrolled, but provided the historical evidence that vincristine is an effective salvage therapy in patients with acquired TTP who do not respond optimally to standard treatment.

We conclude that, on the basis of the literature review VCR is a safe, inexpensive, readily available and rapidly acting agent. Further large prospective studies need to be done to confirm the benefit of its use from the start either alone or as a second line with TPE. We suggest that it should be used from the start together with PE.

\section{References}

1. Furlan M, Robles R, Lammle B (1996) Partial purification and characterization of a protease from human plasma cleaving von Willebrand factor to fragments produced by in vivo proteolysis. Blood 87 : 4223-4234.

2. Lammle B, Kremer Hovinga J, Studt JD (2004) Thrombotic thrombocytopenic purpura. Hematol J 5: S6-S11.

3. Moake JL (2002) Thrombotic microangiopathies. N Engl J Med 347: 589-600.

4. Amorosi EL, Ultmann JE (1966) Thrombotic thrombocytopenic purpura: report of 16 cases and review of the literature. Medicine 45: 139-159.

5. Bell WR, Braine HG, Ness PM, Kickler TS (1991) Improved survival in thrombotic thrombocytopenic purpura-hemolytic uremic syndrome. $\mathrm{N}$ Engl J Med 325: 398-403.

6. Rüfera A, Brodmanna D, Gregora M, Johanna A, Hovingab K, et al. (2007) Rituximab for acute plasma-refractory thrombotic thrombocytopenic purpura : SWISS MED WKLY 137: 518-524.

7. Rock G, Porta C, Pallavicini BE (2000) Thrombotic thrombocytopenic purpura treatment in year 2000. Haematologica 85: 410-419.

8. Kaplan AA, George JN Treatment and prognosis of thrombotic thrombocytopenic purpura-hemolytic uremic syndromes in adults.

9. Han-Mou Tsai (2009) Thrombotic thrombocytopenic purpura, Hemolytic-uremic syndrome, and related disorders.

10. George JN (2006) Clinical practice. Thrombotic thrombocytopenic purpura. N Engl J Med 354: 1927-1935.

11. Kiss JE (2010) Thrombotic thrombocytopenic purpura: recognition and management. Int J Hematol 91: 36-45.

12. Rock GA, Shumak KH, Buskard NA (1991) Comparison of plasma exchange with plasma infusion in the treatment of thrombotic thrombocytopenic purpura. N Engl J Med 325: 393-397.

13. Blitzer JB, Granfortuna JM, Gottlieb AJ (1987) Thrombotic thrombocytopenic purpura: treatment with plasmapheresis. Am J Hematol 24: 329-339.

14. Roberts AW, Gillett EA, Fleming SJ (1991) Hemolytic uremic syndrome/ thrombotic thrombocytopenic purpura: outcome with plasma exchange. J Clin Apher 6: 150-154.

15. Onundarson PT, Rowe JM, Heal JM, Francis CW (1992) Response to plasma exchange and splenectomy in thrombotic thrombocytopenic purpura. A 10-year experience at a single institution. Arch Intern Med 152: 791-796. 
Citation: Elrewihby WH, Zaghloul S, Saber N, Hasan EE, Elattar A (2017) Thrombotic Thrombocytopenic Purpura Refractory to Plasmapheresis Treated Successfully with Vincristine: A Case Report. J Blood Disord Transfus 8: 380. doi:10.4172/2155-9864.1000380

Page 3 of 3

16. Shah N, Rutherford C, Matevosyan K, Shen YM, Sarode R (2013) Role of ADAMTS13 in the management of thrombotic microangiopathies including thrombotic thrombocytopenic purpura (TTP). $\mathrm{Br}$ J Haematol 163: 514-519.

17. Sayani FA, Abrams CS (2015) How i treat refractory thrombotic thrombocytopenic purpura. Blood 125: 3860-3867.

18. Centurioni R, Leoni P (1990) High-dose immunoglobulins in the treatment of thrombotic thrombocytopenic purpura (TTP). Haemathologica 75: 196-197.

19. Tsai HM, Shulman K (2003) Rituximab induces remission of cerebral ischemia caused by thrombotic thrombocytopenic purpura. Eur J Haematol 70: 183-185.

20. Spiekermann K, Wormann B, Rumpf KW, Hiddemann W (1997) Combination chemotherapy with CHOP for recurrent thrombotic thrombocytopenic purpura. Br J Haematol 97: 544-546.

21. Bachman WR, Brennan JK (1996) Refractory thrombotic thrombocytopenic purpura treated with cyclosporine. Am J Hematol 51: 93-94.

22. Musso M, Porretto F, Crescimanno A (1999) Succesful treatment of resistant thrombotic thrombocytopenic purpura/ hemolytic uremic syndrome with autologous peripheral blood stem and progenitor (CD34+) cell transplantation. Bone Marrow Transplant 24: 207-209.

23. Mant MJ, Turner AR, Bruce D, Ritchie D, Larratt LM (1999) Splenectomy during partial remission in thrombotic thrombocytopenic purpura with prolonged plasma exchange dependency. Am J Haematol 62: 56-57.

24. Welborn JL, Emrick P, Acevedo M (1990) Rapid improvement of thrombotic thrombocytopenic purpura with vincristine and plasmapheresis. Am J Hematol 35: 18-21.

25. Levin M, Grunwald HW (1991) Use of vincristine in refractory thrombotic thrombocytopenic purpura. Acta Haematol 85: 37-40.

26. Connor NTJ O, Jones PB, Hill LF (1992) Vincristine therapy for thrombotic thrombocytopenic purpura. Am J Hematol 39: 234-236.
27. Pallavicini EB, Porta C, Centurioni R (1994) The Italian Cooperative Group for TTP Vincristine sulfate for the treatment of thrombotic thrombocytopenic purpura refractory to plasma-exchange. Eur J Haematol 25: 222-226.

28. Gool SV, Brock P, Van Laer P (1994) Successful treatment of recurrent thrombotic thrombocytopenic purpura with plasmapheresis and vincristine. Eur J Pediatr 153:517-519.

29. Mazzei C, Pepkowitz S, Klapper E, Goldfinger D (1998) Treatment of thrombotic thrombocytopenic purpura: a role for early vincristine administration. J Clin Apheresis 13: 20-22.

30. Schultz A, Sitzler HG, Scheid C (1999) A case of thrombotic thrombocytopenic purpura in an adult treated with vincristine. Ann Hematol 78: 39-42.

31. Dagdas S, Ozet G, Yilmaz M (2003) Vincristine as an alternative therapeutic approach for refractory thrombotic thrombocytopenic purpura. Blood Banking Transf Med 1: 43-47.

32. Vukovic NS, Budisin Z, Elezovic I (2005) The successful treatment of refractory thrombotic thrombocytopenic purpura with vincristine: a case report. Haema 8: 300-303.

33. Ferrara F, Copia C, Annunziata M (1999) Vincristine as salvage treatment for refractory thrombotic thrombocytopenic purpura. Ann Hematol 78: 521-523.

34. Gutterman LA, Stevenson TD (1982) Treatment of thrombotic thrombocytopenic purpura with vincristine. JAMA 247: 1433-1436.

35. Abramson N (1978) Treatment for thrombotic thrombocytopenic purpura: plasma, vincristine, hemodialysis and exchange transfusions. $\mathrm{N}$ Engl J Med 298: 971-972.

36. Ziman A, Mitri M, Klapper E, Pepkowitz SH, Goldfinger D (2005) Combination vincristine and plasma exchange as initial therapy in patients with thrombotic thrombocytopenic purpura: one institution's experience and review of the literature. Transfusion 45: 41-49. 